\title{
FATIGUE RESISTANCE OF HIGH-THICKNESS AL-ALLOY SHEETS AFTER WATER JET CUTTING
}

Water jet cutting is a useful advanced technology of separating materials with a great industrial potential due to high cutting speed, precision, shape repeatability and possibilities to be performed automatically with a computer control. It is well known, however, that fatigue properties are particularly strongly affected by surface conditions and quality of surface layer. Water jet cutting was applied to Al-alloy sheets of fairly high thickness, namely $50.8 \mathrm{~mm}$. Fatigue resistance of water cut specimens and failure mechanisms were investigated and compared with those studied using a reference batch of specimens manufactured by fine milling. Character of surface damage caused by water jet cutting resulted in a considerable reduction of fatigue strength in comparison with milled surface. The results are discussed considering microscopic analysis of surface and subsurface conditions of fatigue crack initiation.

\section{Introduction}

Water jet machining (WJM) is an advanced promising technology, which can be used for cutting either metals or other nonmetallic materials like glass reinforced composites, ceramics or even glass plates [1]. This technology, or abrasive water jet machining as its modification, is advantageously used particularly for cutting a variety of difficult-to-machine materials. Since water jet machining systems are quite expensive, new methodologies are being developed to enable to use advantages of water jet machining in small and medium enterprises [2]. Surface and kerf quality after water jet machining always has to be evaluated for specific applications from the point of view of both material and technological parameters, because existing knowledge about water-jet cutting and machining is still ambiguous [3]. WJM is usually connected with surface unevenness, with typical texture marks called striations [4], whose character depends on water jet parameters. Generally, striations arise for three reasons, namely the nature of the step formation inherent to a jet cutting process, the dynamic characteristics of the water jet, and the vibration of the machining system [5]. As an example, in case of abrasive WJM, formation of striations and surface quality depends on distribution of particles in the water jet [6]. Surface quality after WJM and kerf parameters are strongly affected by nozzle diameter and also by number of waves in water flow [1].

It is known that surface quality and roughness generally significantly affects fatigue behaviour, as fatigue crack initiation process is mostly located in material surface layers [7, 8]. A specific effect of the surface quality is, however, connected with numerous other parameters like surface strength, microstructure, material notch sensitivity, surface and subsurface residual stresses etc. Though computer models for an evaluation of effects of surface roughness on fatigue resistance have been recently developed [9], actual effects are usually investigated and have to be verified using experimental methods. In most cases, increased surface roughness reduces fatigue limit and fatigue strength. However, it can have only negligible effect, if the roughness is not too big and other fatigue crack initiation mechanisms occur [10].

The work presented in this paper was performed in the context of the knowledge presented in the literature. It was aimed at an experimental investigation of an effect of water jet cutting with specific parameters applied to an Al-alloy sheet of quite big thickness on fatigue behaviour and resistance.

\section{Experiments}

The experimental material was quite thick sheet of Al-alloy 2124 T851 of the thickness $50.8 \mathrm{~mm}$. Water jet contained abrasive particles. Cutting speed was $81 \mathrm{~mm} / \mathrm{min}$. Besides specimens machined by the water jet technology, reference specimens manufactured by classical mechanical machining, by fine milling, were prepared and tested to compare the two methods.

Fatigue tests were performed on SCHENCK PHG $3000 \mathrm{~N}$ machine under three point bending (3PB) with load asymmetry $R=0.1$, test span $62 \mathrm{~mm}$, load frequency $40 \mathrm{~Hz}$ (Fig. 1). The specimens were of square cross section $7 \times 7 \mathrm{~mm}$. To exclude possible effects of the position in the thick sheet, three groups of specimens were tested, namely those taken from the top nearsurface layer, from the center and from the bottom layer.

\footnotetext{
* Ivo Cerny, Dagmar Mikulova

SVUM a.s., Areal VU 565, CZ-19011 Praha 9, Czech Republic, E-mail: Ivo.Cerny@seznam.cz
} 


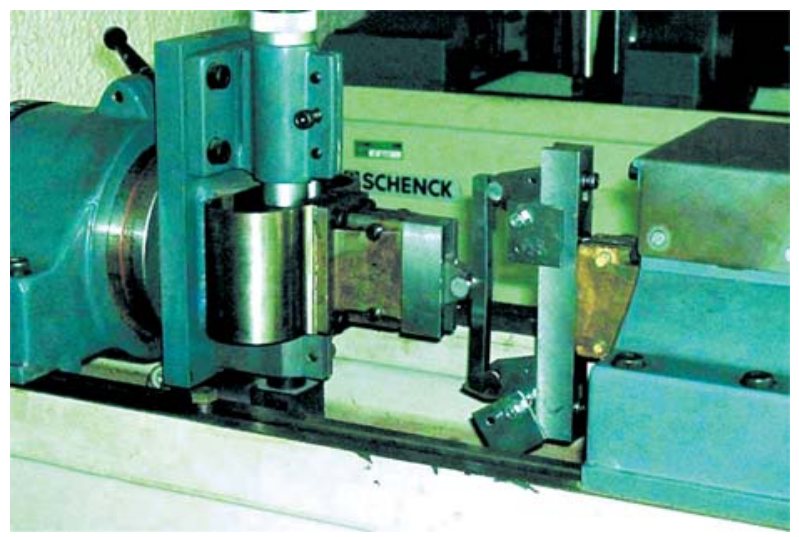

Fig.1 Three-point-bend specimen on the SCHENCK machine

Microstructure analyses were performed using optical microscopes Olympus and Neophot 21, respectively, both with computer digital image processing. Additionally, fractographical and some other analyses were performed using scanning electron microscope JEOL JSM-35, also equipped with digital image processing.

\section{Results and discussion}

\subsection{Cutting surface quality}

As regards character of surface area of the thick sheet examined by visual check, the striation phenomenon could be distinctly observed. In Fig. 2, where water jet direction was from bottom to top, there are almost no striations in the bottom area, i.e. in the area of water jet input, unlike distinct striation relief in the top area. A similar relief also was described in [11] - superior surface quality in the jet input region and rough surface in the jet outlet zone. However, it will be shown later that the coarse striation relief was not the most important phenomenon affecting fatigue behaviour.

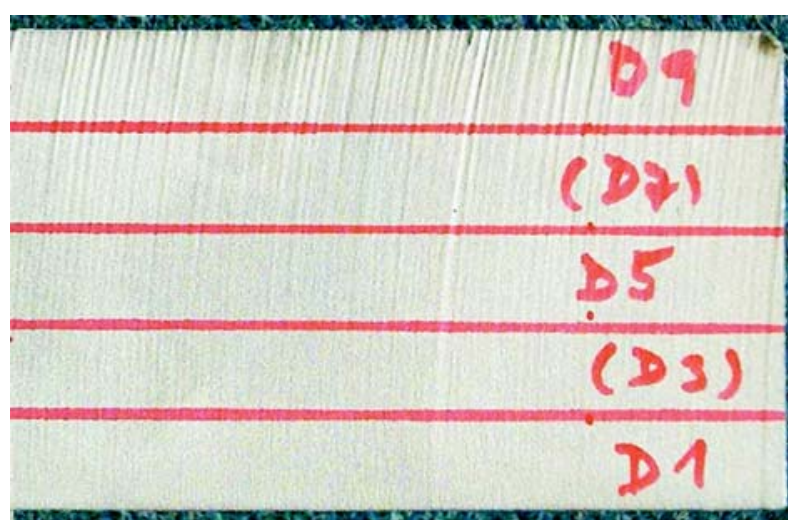

Fig. 2 Visual check of water jet cutting surface with distinct striations in the jet outlet area - the top

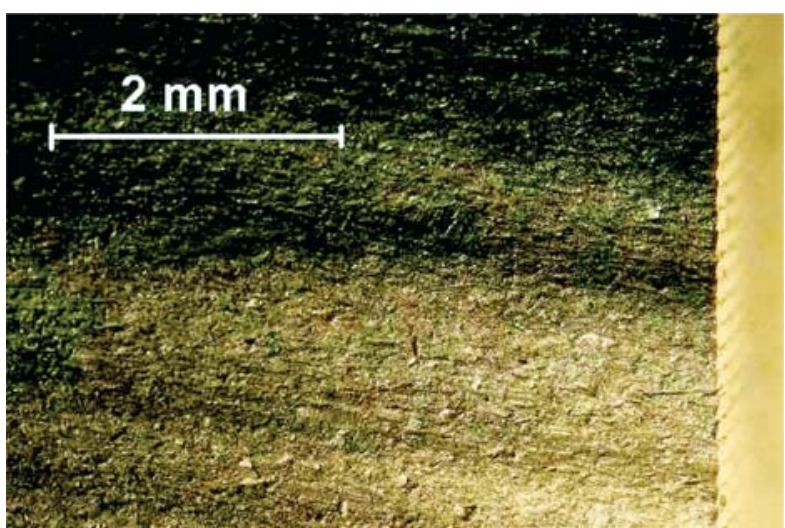

Fig. 3 Macroscopic view of water jet cutting surface with large striations and microscopic roughness

From the macroscopic and microscopic points of view, quite significant differences between machining and water jet cutting were observed. Typical character of water jet cutting surface is shown in Fig. 3. Even the macroscopic analysis indicated that besides the rough striations observable by eye without magnification (Fig. 2), with a typical mutual distance of individual unevenness peaks between $1-1.5 \mathrm{~mm}$, the water jet cutting surface was characteristic by another type of roughness, more microscopic, which could be described like "secondary roughness". Fine milling of the specimens taken from the thick sheet was connected with a distinct macroscopic surface relief, but without the microscopic "secondary roughness". The mutual distance of roughness peaks was approximately $0.2 \mathrm{~mm}$ - Fig. 4 .

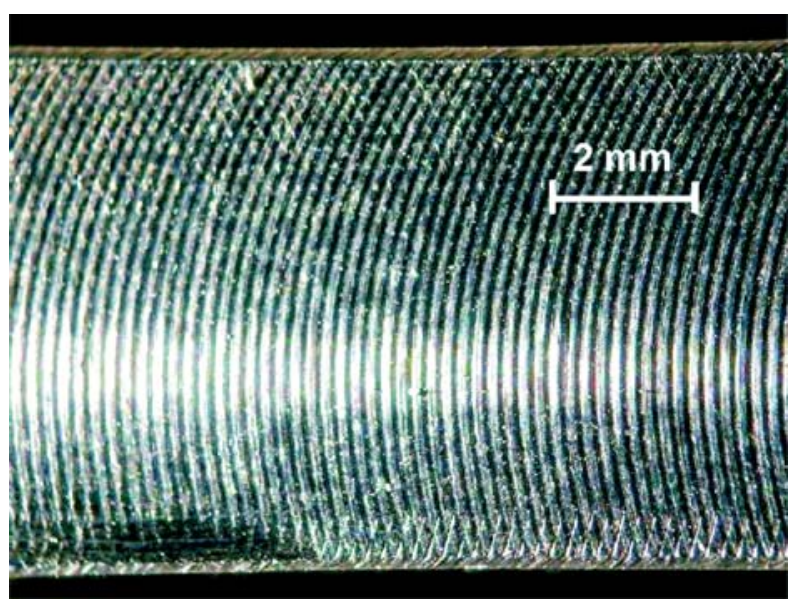

Fig. 4 Character of milled surface

Microscopic analysis was carried out on longitudinal cuts of the specimens. In case of water jet cutting surface, it was shown that the microscopic surface roughness was connected with an unfavourable feature as regards fatigue resistance: an existence of microcracks and sharp micronotches - Fig. 5. In the contrary, notches caused by fine milling were just shallow, without sharp 
edges. The character of milled surface analysed on longitudinal cut is in Fig. 6. Another factor, which was found to be important as regards fatigue resistance and mechanisms of initiation of fatigue cracks, was a presence of quite large particles of intermetallic phases, which is for this type of Al-alloy quite typical.

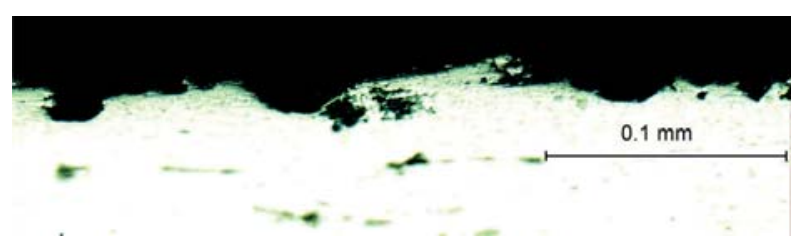

Fig. 5 Microscopic character of water jet cutting surface on longitudinal cut

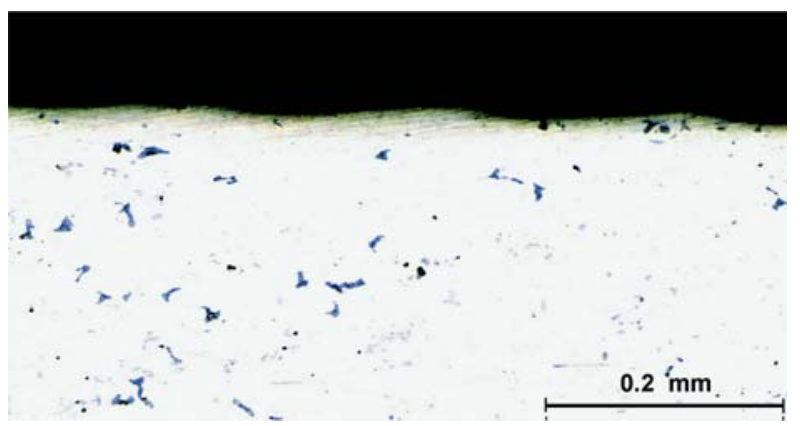

Fig. 6 Milled surface documented on longitudinal cut, showing just shallow notches and quite dense occurrence of large intermetallic particles

\subsection{Results of fatigue tests}

Results of fatigue tests of specimens with milled surface are in Fig. 7. Individual specimens are marked with letters and figures, the letters indicating position in the sheet $(\mathrm{H}-$ top, $\mathrm{S}$ - center, D - bottom). Since no distinct dependence of fatigue resistance on this position was ascertained, all the experimental points were plotted together. Fatigue limit of machined specimens was almost $300 \mathrm{MPa}$, which is quite a high value considering the fact that the

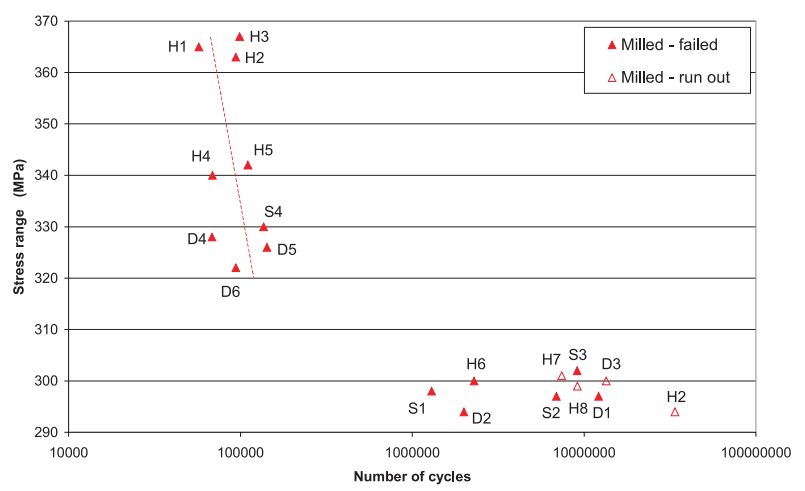

Fig. 7 Fatigue $S$ - $N$ curve of specimens with milled surface surface only was milled with no further improvement like grinding. Statistical analysis showed no significant effects of the position in the sheet, either near two surfaces or in the sheet center, fatigue properties of the sheet along the thickness were homogenous. Therefore, all the points were plotted in the same diagram with the same symbol. Individual points in Fig. 7 were amended with corresponding specimen marking to enable further more detailed analysis of fatigue life and crack initiation mechanisms.

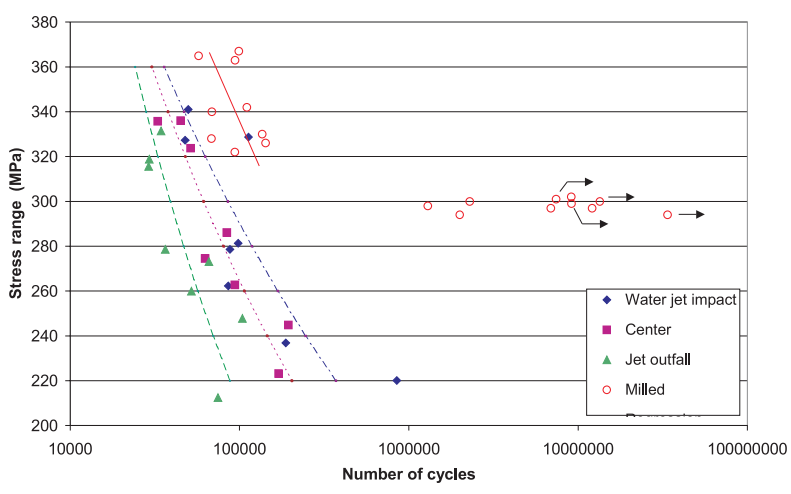

Fig. 8 Results of fatigue tests of specimens with water jet cutting surface in comparison with milled specimens

Fatigue S-N curve of specimens with water jet cutting surface is documented in Fig. 8. Water jet cutting deteriorated fatigue resistance very significantly. In general, fatigue strength corresponded to just about $65 \%$ of fatigue strength of milled specimens. Analysing the results more in detail, further characteristic features of the S$\mathrm{N}$ curve were found. The unfavourable effect of water jet cutting was observed not only with stress range near the fatigue limit of milled specimens, $300 \mathrm{MPa}$, but also in the area of high amplitudes and limited fatigue life. Moreover, there was distinct and statistically significant dependence of fatigue life on the position of specimen in the sheet from the viewpoint of water jet input or outlet: Specimens near the jet outlet, i.e. those taken from the area of rough water jet striations, had the poorest fatigue resistance, whereas these differences were more distinct in the region of lower stress amplitudes.

\subsection{Analyses of fatigue cracking mechanisms}

Differences between individual points of fatigue life of milled specimens as well as reasons of the unfavourable effect of water jet cutting applied to the thick sheet were evaluated analysing fracture surface, particularly by scanning electron microscopy (SEM).

Looking at the area of limited fatigue life of milled specimens in Fig. 7, some scatter can be seen. Fractographical analysis of crack initiation sites was performed with two different specimens, namely $\mathrm{H} 3$ with higher-average fatigue life and $\mathrm{H} 4$ with bellowaverage life. Figs. 9 and 10 indicate reasons of the different fatigue 
resistance. Character of crack initiation areas is quite different. In Fig. 9, specimen $\mathrm{H} 3$, fatigue crack was initiated on the surface of maximum stress amplitude, on just a small intermetallic particle. Fig. 10 shows that in specimen $\mathrm{H} 4$ with the bellow-average fatigue resistance, fatigue crack initiation occurred at the specimen edge and it was caused by local cumulation of intermetallic particles in this area causing a local reduction of fatigue resistance and fairly premature crack initiation.

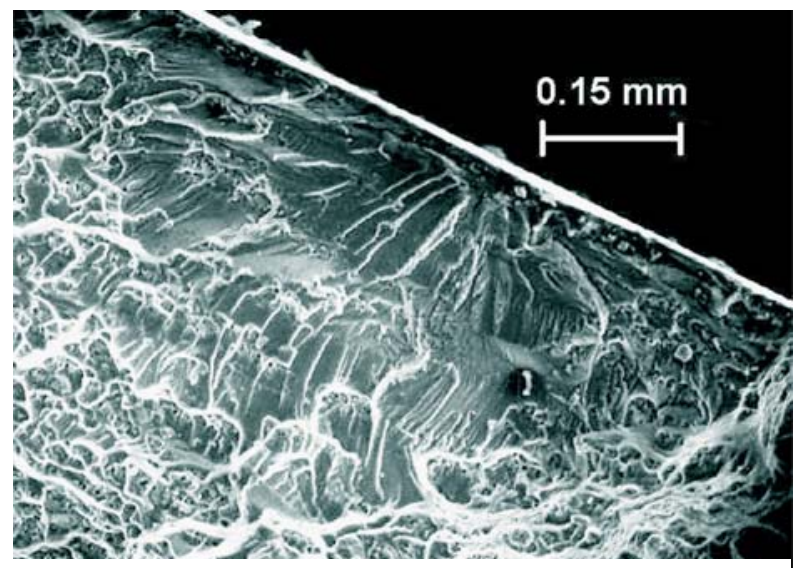

Fig. 9 Crack initiation on small particles in specimen H3 with above-average fatigue life

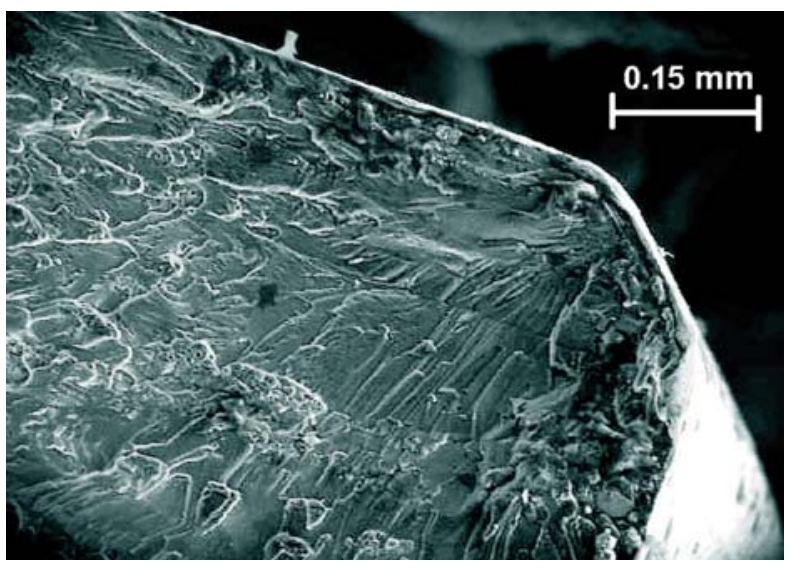

Fig. 10 Crack initiation near edge supported by cumulation of particles in vicinity - specimen $\mathrm{H} 4$

Quite a lot of specimens were tested at stress range $300 \mathrm{MPa}$, close to fatigue limit - Fig. 7. Six of them failed whilst the other four did not. Fractographical analysis of specimen H6, failed after more than 2 million cycles, indicated failure mechanism - Fig. 11. Fatigue crack was initiated in the subsurface area near specimen edge on cumulation of intermetallic particles. The initiation site was located approximately $0.15 \mathrm{~mm}$ under the surface. The subsurface initiation mechanism likely affected the retarded failure, after more than 2 million cycles. Retarded failure is quite a typical phenomenon for subsurface crack initiation [12].

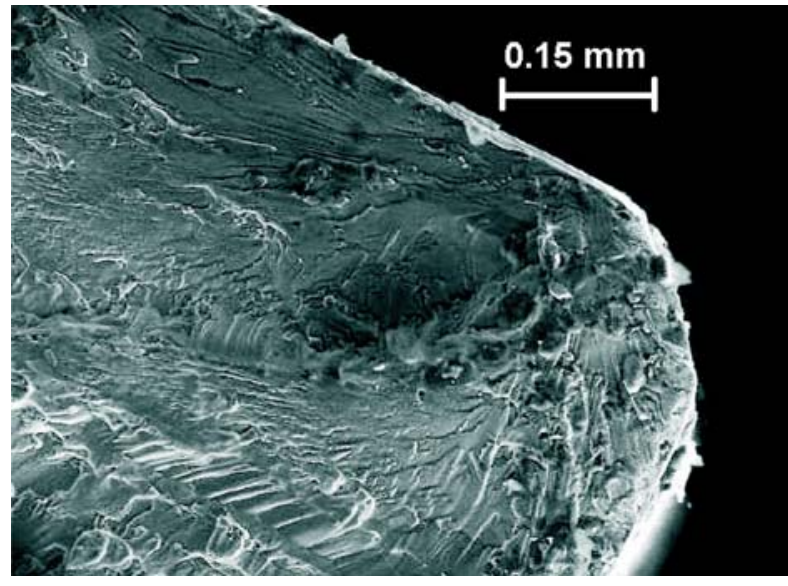

Fig. 11 Subsurface crack initiation in specimen H6 failed during test at stress range near fatigue limit

Analysing the surface of water jet cut specimens with fairly high magnifications, it could be observed that the rough surface (the "secondary roughness" mentioned above) actually contained a lot of sharp notches or surface microcracks, which became initiation sites of fatigue cracks. An initiation site of a main crack with the damaged surface area close to the site is in Fig.12. The initiation area is marked with the arrow. The surface sharp notches and microcracks accelerated the fatigue crack initiation process so strongly that multiple fatigue cracking could be observed. It follows from the diagram in Fig. 8 that the macroscopic surface striation phenomenon, mentioned in the literature as an important type of damage caused by water jet machining [11] and observed also in this work, only had a minor effect on fatigue strength in comparison with the microscopic surface damage by the sharp notches and microcracks.

Considering failure mechanisms, when fatigue crack initiation was either caused or supported by intermetallic particles or by their surface or subsurface cumulation, it could be concluded

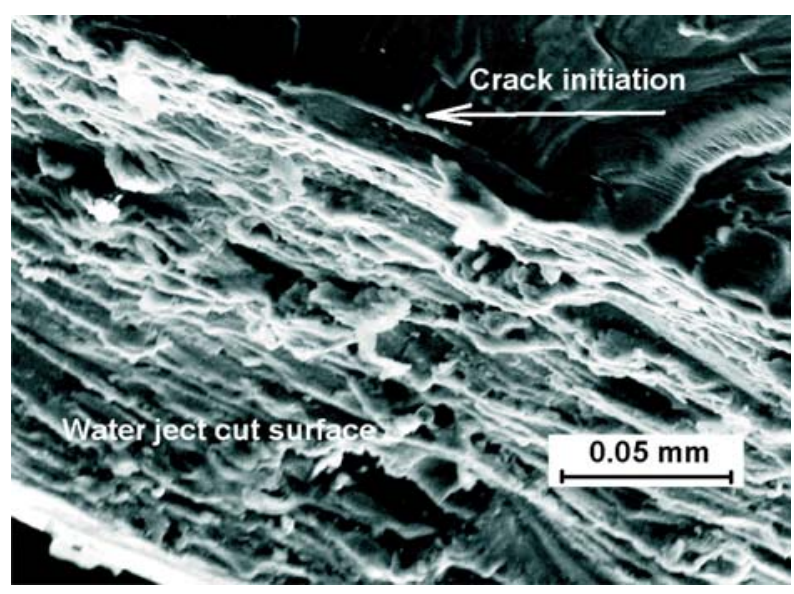

Fig. 12 Characteristic crack initiation site in one of numerous sharp micropits and micronotches caused by water jet cutting 
that fatigue resistance in the specific studied case is dependent more on the material resistance against growth of physically short fatigue crack than on the resistance against crack initiation [13].

\section{Conclusions}

An experimental investigation of an effect of abrasive water jet cutting with specific parameters applied to an Al-alloy 2124 T851 sheet of the thickness $50.8 \mathrm{~mm}$ on fatigue resistance was carried out. Reference specimens manufactured by classical mechanical machining, namely fine milling, were tested to compare the two methods. The most important results can be summarised as follows:

- The milling operation resulted in a characteristic surface relief created by shallow notches without further microscopic roughness. Fatigue cracks were initiated mostly on surface or subsurface particles of intermetallic phases. Fatigue life was lower in case of crack initiation on large particles or cumulation of particles in comparison with the initiation on smooth surface or just small particles. Subsurface initiation on cumulation of particles in specimens tested at stress amplitude close to fatigue limit was connected with retarded failure, even more than 107 cycles.
- The abrasive water jet cutting resulted in a rough cutting surface of the sheet. Besides striations visible by eye, numerous microscopic sharp notches and micropits of a big density could be observed on the surface.

- The water jet cutting technology applied to the thick sheet resulted in a significant reduction of fatigue strength, by about $35 \%$. Fatigue cracks initiated in some of the numerous surface sharp notches and microcracks, whereas multiple fatigue crack initiation was observed.

The results showed that for this type of sheet, water jet cutting cannot be used as a final technology operation without further surface treatment, if the component or part will be exposed to considerably variable stress. The actual fatigue resistance looks to be affected more by resistance of the material against growth of physically short cracks or by notch sensitivity, respectively, than by resistance against fatigue crack initiation on smooth surface.

\section{Acknowledgement}

The work has been carried out within the project supported by the Czech Ministry of Education, Youth and Sport under grant MSM 2579700001

\section{References}

[1] ZHU, H. T., HUANG, C. Z., WANG, J., LU, X. Z., FENG, Z. X.: Mach Inability of Glass by Abrasive Water Jet, Int. J. of Materials and Product Technology, Vol. 31, 1/2007, pp.106-112

[2] GEREN, N., BAYRAMOGLU, M., ESME, U.: Improvement of a Low-Cost Water Jet Machining Intensifier Using Reverse Engineering and Redesign Methodology, J. of Engineering Design, Vol. 18, 1/2007, pp. 13-37

[3] JOU M.: Analysis of The Stability of Water-Jet Cutting With Linear Theory, J. of Materials Processing Technology, Vol. 104, 1/2000, pp. 17-20

[4] CHEN, F. L., SIORES, E.: The Effect of Cutting Jet Variation on Surface Striation Formation in Abrasive Water Jet Cutting, J. of Materials Processing Technology, Vol. 135, 1/2003, pp. 1-5

[5] CHEN, F. L., WANG, J., LEMMA E., SIORES, E.: Striation Formation Mechanisms on The Jet Cutting Surface, J. of Materials Processing Technology, Vol. 141, 2/2003, pp. 213-218.

[6] CHEN, F. L., SIORES, E.: The Effect of Cutting Jet Variation on Striation Formation in Abrasive Water Jet Cutting. Int. J. of Machine Tools and Manufacture, Vol. 41, 10/2001, pp. 1479-1486

[7] KLESNIL, M., LUKAS, P.: Fatigue of Metallic Materials under Mechanical Loading, $1^{\text {st }}$ ed., 224 p., 1975, Praha, Academia [in Czech].

[8] POLAK, J.: Cyclic Plastic response and fatigue Life of Materials, Key Engng. Materials, Vol. 348-349, 2007, pp. 113-116

[9] YUUTA, A., HIROSHI, N.: Fatigue Limit Reliability of Axisymmetric Complex Surface, Int. J. of Fracture, Vol. 131, 1/2005, pp. 59-78

[10] ITOGA, H., TOKAJI, K., NAKAJIMA, M., KO, H.-N.: Effect of Surface Roughness on Step-Wise S-N Characteristics in High Strength Steel, Int. J. of Fatigue, Vol. 25, 5/2003, pp. 379-385

[11] LEBAR, A., JUNKAR, M.: Simulation of Abrasive Water Jet Cutting Process: Part 1. Unit event approach, Modelling and Simulation in Materials Science and Engineering, Vol. 12, 6/2004, pp. 1159-1170

[12] NOVY, F., CINCALA, M., KOPAS, P., BOKUVKA, O.: Mechanisms of High-Strength Structural Materials Fatigue Failure in UltraWide Life Region, Materials Science and Engineering, Vol. A 462, 2007, p. 189-192

[13] BOKUVKA, O., NOVY, F., CINCALA, M., KUNZ, L.: Gigacycle Fatigue of Structural Materials (in Slovak), Acta Mechanica Slovaca, Vol. 10, 1/2006, pp. 53-58 